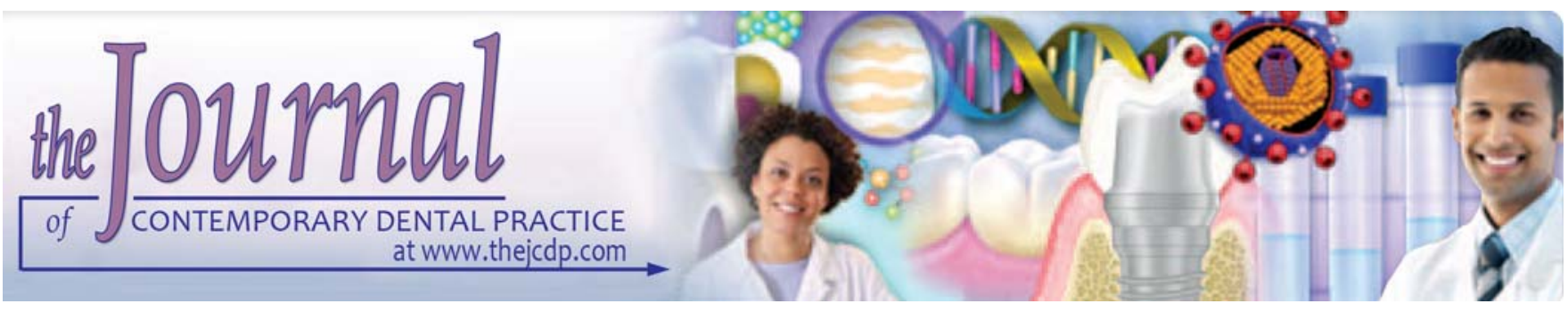

\title{
Clinical Effect of a Mouth Rinse containing Ocimum gratissimum on Plaque and Gingivitis Control
}

\author{
Sérgio Luís da Silva Pereira, José Weslley Gonçalves de Oliveira, Keyles Karla Sá Vieira Ângelo \\ Ângela Maria Alves da Costa, Flávio Costa
}

\begin{abstract}
Aim: The effect of Ocimum gratissimum $(O g)$ on the reduction of dental plaque and gingivitis was evaluated in a randomized, parallel and double-blind clinical trial.

Materials and methods: Subjects were randomly allocated to the control group $(n=10)$ - mouth rinse with no antiseptic agents; CLX group $(n=10)$ - mouth rinse containing chlorhexidine digluconate or Og group $(n=10)$-mouth rinse containing Ocimum gratissimum. Plaque (PLI) and bleeding $(\mathrm{BI})$ indexes were assessed at days 0 and after 3 months. Subjects were asked to brush their teeth with a fluoridated dentifrice, three times a day, during a 90-day period. After each brushing they rinsed with one of the three mouth rinses during 1 minute.
\end{abstract}

Results: There was a significant reduction on plaque and gingivitis in tests groups $(p<0.05)$, but no statistically significant difference was observed among them $(p>0.05)$.

Conclusion: Mouth rinse containing Og was effective as antiplaque and antigingivitis agent, in a similar manner that chlorhexidine digluconate.

Clinical significance: Research in treatment of chronic oral diseases using natural agents must be encouraged to verify which would be a useful addition to the current range of chemotherapeutic treatment options.

Keywords: Dental plaque, Gingivitis, Ocimum gratissimum, Randomized controlled clinical trial.

How to cite this article: da Silva Pereira SL, de Oliveira JWG Ângelo KKSV, da Costa ÂMA, Costa F. Clinical Effect of a Mouth Rinse containing Ocimum gratissimum on Plaque and Gingivitis Control. J Contemp Dent Pract 2011;12(5):350-355.

Source of support: Nil

Conflict of interest: None declared

\section{INTRODUCTION}

Gingivitis is one of the most prevalent infectious oral diseases in humans associated with dental plaque. ${ }^{1}$ Afterward, the removal of bacterial biofilm is a crucial component in the prevention and treatment of this disease. ${ }^{2}$
Mechanical plaque control is a simple and cost-effective method that has been showed to be efficient in gingivitis control; ${ }^{2-4}$ however, its effectiveness is influenced by the individual's manual ability and motivation. ${ }^{2}$ For the reason, there is a great interest to search antimicrobial agents in order to replace or to be adjuncts to the mechanical approaches. These chemicals, mainly triclosan and chlorhexidine, have been used to avoid plaque formation and development of gingivitis ${ }^{5-8}$ and are often recommended in situations in which oral hygiene is difficult, compromised or impossible. ${ }^{9}$ As some of these substances may have undesirable side effects, such as tooth staining and taste alteration, herbal agents with antimicrobial and antiinflammatory properties have been investigated and showed varied results. ${ }^{10-15}$

Higher and aromatic plants have traditionally been used in folk medicine, showing inhibition against several group of microorganisms. ${ }^{16}$ Plants from Brazil biomes have also been used as natural medicines by local populations in the treatment of several tropical diseases, including fungal and bacterial infections. ${ }^{16}$

Among the various available herbal agents, Ocimum gratissimum $(\mathrm{Og})$, originating in the Orient, is widely distributed in tropical and warm temperature regions, including Brazil, where it is popularly known as 'alfavacacravo. ${ }^{17} \mathrm{Og}$ belongs to the group of plants known as spices and it is an erect small plumb with many barnacles usually not more than $1 \mathrm{~m}$ high. ${ }^{18}$ It is of the family Labiatea, genus Ocimum and species gratissimum, ${ }^{18}$ and it is commonly used in folk medicine to treat different diseases, e.g. skin diseases, pneumonia and also as a treatment for cough, fever and conjunctivitis. ${ }^{19,20}$ However, genetic material, culture conditions and environment are important factors to its effectiveness as therapeutic agent. ${ }^{16}$ 
Laboratorial previous studies showed that $O g$ presents antimicrobial, ${ }^{18,19}$ antinociceptive and anti-inflammatory activities, ${ }^{20}$ showing that this herbal agent can be effective against acute and chronic oral diseases.

At the time of the present work, there is no reported controlled trial evaluating the efficacy of $O g$ in the control of plaque and gingivitis. Thus, the aim of the present study was to assess the antiplaque and antigingivitis effects of this phytotherapeutic agent in comparison to digluconate chlorhexidine.

\section{MATERIALS AND METHODS}

\section{Subjects}

Thirty adult subjects from the University of Fortaleza (15 females and 15 males aged 27 to 42 years) were enrolled in this double-blind, parallel, controlled clinical trial. All randomly screened participants were informed about the nature of the study and signed an informed consent form in compliance with the guidelines of the Brazilian National Health Council. The protocol was approved by the Institutional Ethics Committee (Report Coética/Unifor: 161/ 2009).

The subjects were entered in the study if they had bleeding index $(\mathrm{BI})^{21} \geq 20 \%$, presence of at least 20 natural teeth and absence of supragingival calculus and other plaque retentive factors, such as carious cavity and restoration excess. Participants with medical disorders and under antimicrobial therapy, as well as smokers, pregnant women and individuals presenting a probing depth $\geq 3 \mathrm{~mm}$ were excluded from the trial.

\section{Tests and Control Products}

The control and tests mouth rinses were formulated and packed into bottles in the Pharmaceutics' Laboratory at the University of Fortaleza. The bottles were previously coded to warrant that neither the examiner nor the participants knew their content, which was revealed by the pharmacist only after the study was completed. All subjects used just one of these mouth rinses, according to a parallel study.

The control mouth rinse was constituted by triethanolamine (q.s.p.), alcohol, water (q.s.p.), nipagin (0.2\%), glycerin (2.5\%), aspartame (q.s.p.), presenting color and taste similar to those used in the tests of mouth rinses. These had the same formulation, adding $0.12 \%$ digluconate chlorhexidine (CLX group) or Og (Og group).

\section{Experimental Design}

The participants were assigned to either control group $(\mathrm{n}=10)$ or the tests groups-CLX group $(\mathrm{n}=10)$ and $O g$ group $(\mathrm{n}=10)$-by random permutation of three. The volunteers were examined for plaque and gingivitis at baseline and after 3 months. A single, previously calibrated examiner scored the BI and the plaque index (PLI), ${ }^{22}$ which were recorded on the buccal, mesial, distal and lingual surfaces of all teeth. The values of four sites of each tooth were averaged to determine the BI and PLI for each subject. In addition to this examination, the hard and soft oral tissues were visually inspected for the presence of any adverse reaction by the same examiner.

After the initial examination, all teeth of each subject were polished with pumice and flossed to eliminate plaque remnants. A personal 'kit' containing a new toothbrush (Leader $^{\circledR}$, Facilit Odontológica e Perfumaria Ltda., Rio de Janeiro, RJ, Brazil), a commercial dentifrice with no antiinflammatory properties (Sorriso ${ }^{\circledR}$, Kolynos do Brazil Ltda., Osasco, SP, Brazil) and tests or control mouth rinses was given to all participants. They were instructed to brush their teeth for 1 minute, three times a day, using their habitual technique. Additionally, after each brushing the participants rinsed with one of the formulations ( $10 \mathrm{ml}, 1 \mathrm{~min}, 3 \times /$ day). Verbal and written instructions about the correct use of hygiene products were given to all subjects as well. In addition to verbal instructions, the students were given recommendations to follow at home. On the last day of experimental phase (90th day), the indexes were recorded and the teeth were polished with pumice.

\section{Statistical Analysis}

ANOVA and Student Newman-Keuls test were performed to evaluate statistical differences between control and tests groups on days 0 and $90(\alpha=0.05)$. In each group, the mean scores of all indexes were compared between baseline and the end of the trial by the paired t-test $(\alpha=0.05)$. However, for illustration, the results are presented as mean and standard deviation.

\section{RESULTS}

All the participants completed the trial. The tests mouth rinses had a good acceptance and did not show formation of abscess, ulcerations or allergic reactions. However, three volunteers from CLX group reported pigmentation and temporary taste disturbance.

At the beginning, there was no statistically significant difference between the control and tests groups with respect to PLI and BI ( $p>0.05)$ means. These results indicated that all groups were well balanced at baseline (Tables 1 and 2), displaying around $25 \%$ of gingival bleeding. At the 90th day, there was a statistically significant difference between control and tests groups for the PLI and BI $(\mathrm{p}<0.05)$ (Tables 1 and 2; Fig. 1).

Comparing the means between baseline and day 90 in each group, there was statistically significant difference in BI and PLI indexes for CLX and Og group ( $<<0.05)$, but with no difference between them ( $\mathrm{p}>0.05$ ) (Tables 1 and 2; Fig. 1). 


\begin{tabular}{lcccc} 
& \multicolumn{4}{c}{ Table 1: Plaque index (PLI) means and standard deviation on day 0 and day 90 for the control and test groups } \\
\hline & Og & $C L X$ & Control & $95 \% \mathrm{Cl}$ \\
\hline Day 0 & $1.08 \pm 0.56 \mathrm{~A}, \mathrm{a}$ & $1.55 \pm 0.79 \mathrm{~A}, \mathrm{a}$ & $1.59 \pm 0.79 \mathrm{~A}, \mathrm{a}$ & $-0.0916-1.0296$ \\
Day 90 & $0.62 \pm 0.26 \mathrm{~A}, \mathrm{~b}$ & $0.55 \pm 0.29 \mathrm{~A}, \mathrm{~b}$ & $1.69 \pm 0.83 \mathrm{~B}, \mathrm{a}$ & $-0.3016-0.1596$ \\
\hline
\end{tabular}

Notes: Means followed by the same uppercase letter $(A)$ in the same line do not differ statistically $(p>0.05)$

Means followed by different lowercase letters $(a, b)$ in the same column differ statistically $(p<0.05)$

\begin{tabular}{lcccc}
\multicolumn{5}{c}{ Table 2: Bleeding Index $(\mathrm{BI})$ means and standard deviation on day 0 and day 90 for the control and test groups } \\
\hline & $\mathrm{Og}$ & $\mathrm{CLX}$ & Control & $95 \% \mathrm{Cl}$ \\
\hline Day 0 & $0.22 \pm 0.04 \mathrm{~A}, \mathrm{a}$ & $0.27 \pm 0.02 \mathrm{~A}, \mathrm{a}$ & $0.23 \pm 0.07 \mathrm{~A}, \mathrm{a}$ & $-0.0592-0.0357$ \\
Day 90 & $0.08 \pm 0.02 \mathrm{~A}, \mathrm{~b}$ & $0.06 \pm 0.03 \mathrm{~A}, \mathrm{~b}$ & $0.24 \pm 0.08 \mathrm{~B}, \mathrm{a}$ & $-0.2033-0.1187$ \\
\hline
\end{tabular}

Notes: Means followed by the same uppercase letter $(A)$ in the same line do not differ statistically $(p>0.05)$

Means followed by different lowercase letters $(a, b)$ in the same column differ statistically $(p<0.05)$

The relation between PLI and BI is shown in Figures 2 to 4 . The linear regression coefficients were $\mathrm{R}^{2}=0.21$, $\mathrm{R}^{2}=0.84$ and $\mathrm{R}^{2}=0.66$ for the $O g$, CLX and control groups respectively. A relation between both indexes was observed for the CLX and control groups but not for the $O g$ group, indicating that its antimicrobial and anti-inflammatory actions occurred independently.

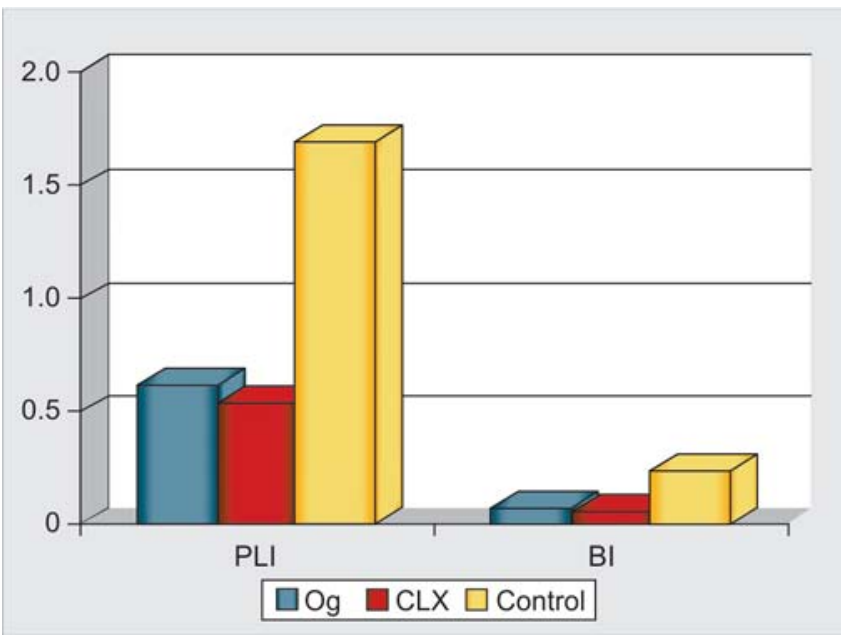

Fig. 1: PLI and $\mathrm{BI}$ scores at day 90 for the control and tests groups

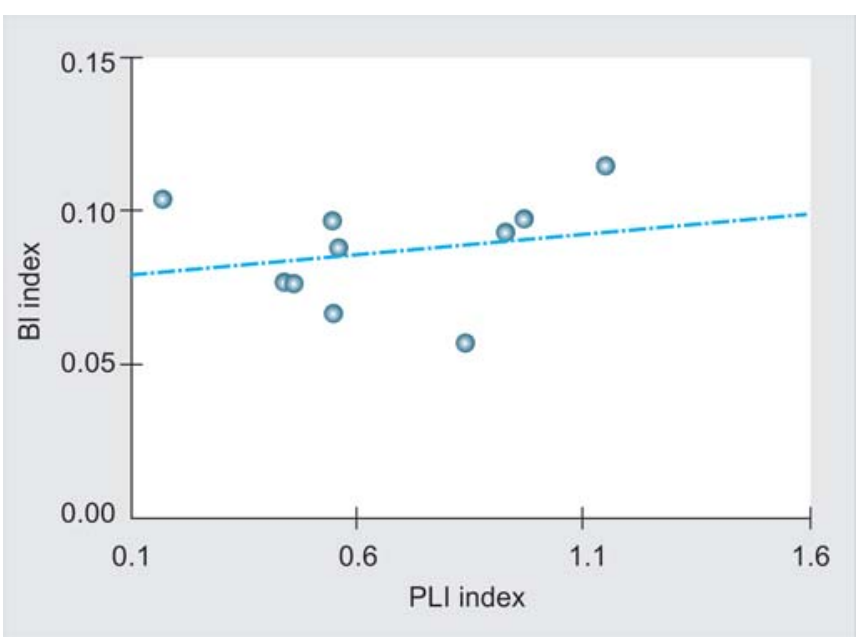

Fig. 2: Linear regression analysis between $\mathrm{PLI}$ and $\mathrm{BI}$ index for Og group at day 90

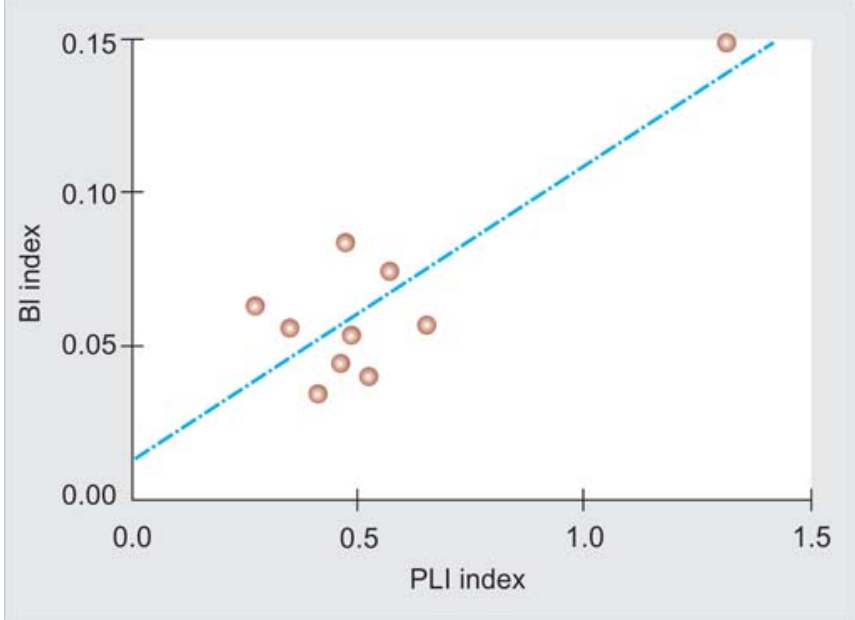

Fig. 3: Linear regression analysis between PLI and BI index for CLX group at day 90

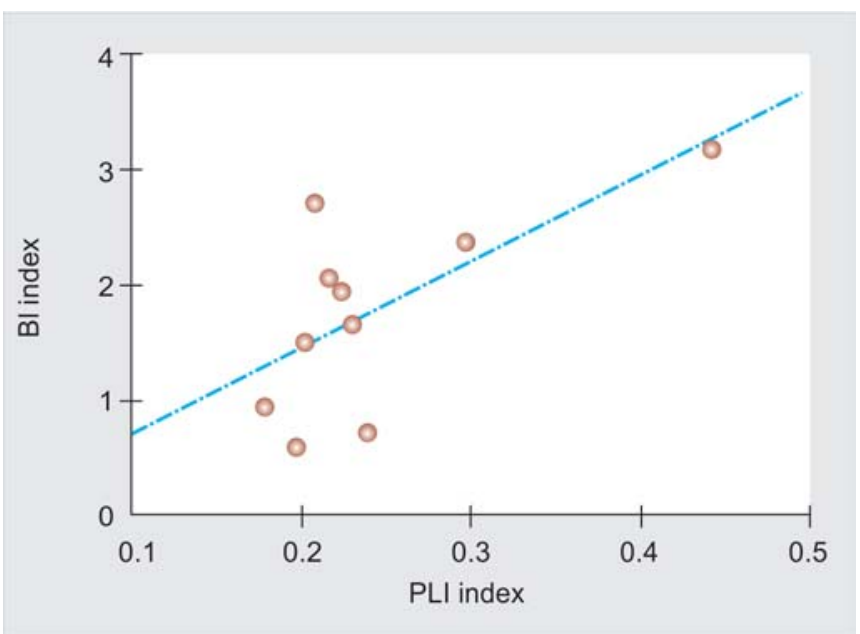

Fig. 4: Linear regression analysis between $\mathrm{PLI}$ and $\mathrm{BI}$ index for control group at day 90

\section{DISCUSSION}

This paper presents the data of a randomized, parallel, double-blind clinical study where a phytotherapeutic agent was used as an adjunct to tooth brushing in a group of patients with gingivitis, comparing it with chlorhexidine 
digluconate. This study design was based on previous studies and it was chosen in order to generate the best possible clinical evidence. ${ }^{13,15}$

In the control group, PLI and BI stayed in the same baseline levels at the end of the experiment, indicating the inability of this adult population to perform adequate tooth cleaning, which is still the gold standard for patients that have the capacity of performing it. ${ }^{2,5}$ In contrast with other studies, in which the patients were instructed to use Bass technique, ${ }^{15,23}$ the usual tooth brushing was not modified to avoid hide the test agents's actual effect.

Chlorhexidine mouth rinse is considered as the golden standard for oral antiseptics and its effectiveness was observed in the present and other studies. ${ }^{2,9,24,25}$ In terms of plaque accumulation, several studies did not find differences between 0.12 and $0.20 \%$ chlorhexidine concentrations. ${ }^{2,24,26,27}$ In the present work, it was used the $0.12 \%$, that is the generally used in commercial mouth rinses. Lower concentrations of chlorhexidine should be prescribed since higher concentrations do not seem to generate lower plaque and gingivitis scores. ${ }^{2}$

Unfortunately, chlorhexidine, as most active antiseptics, has some disadvantages such as discoloration in proximal areas and tongue and reversible effect on the taste. ${ }^{9,23,24}$ In the present study, these aspects were observed in $30 \%$ of the participants and it is in accordance with Botelho et al. ${ }^{13}$

In recent times, report of a number of medicinal herbs used in the treatment and prevention of gingivitis have been published worldwide, presenting limited ${ }^{11,15,23,28}$ and encouraging results. ${ }^{13,14,29,30}$ Despite its commercial use in pharmaceutical industries, ${ }^{16}$ there is a lack of data to support the antigingivitis and antiplaque claims about $\mathrm{Og}$. The absence of adverse effects using this herbal agent in the present study showed that it was well tolerated, supporting safety for the clinical use.

To the best of our knowledge, the present work is the first to evaluate the effect of a mouth rinse containing $\mathrm{Og}$ on plaque accumulation and gingivitis. The results showed that both tests groups were efficient on plaque reduction (64\% in CLX group and 43\% in Og group). This percent difference was not significant at the end of the trial. Conversely, the control group presented a higher percent increase of $12 \%$, but not significant, on plaque accumulation.

Various extracts of $O g$ have been tested in vitro and shown to be active against some bacteria and fungal isolates. ${ }^{18,31,32}$ Nakamura et $\mathrm{al}^{19}$ found that the essential oil of $\mathrm{Og}$ has antibacterial activity against $S$. flexineri, E. coli and Proteus mirabililis. Silva et a ${ }^{33}$ demonstrated that this phytotherapeutic exhibited antifungal activities against dermatophytes, in concordance with the study of Lemos et al. ${ }^{34}$
In the susceptibility test in vitro, $O g$ inhibited the growth of oral microorganisms ${ }^{32,35}$ which allows us to deduce that this phytotherapeutic could be used as antiplaque agent. When prepared as components of mouth rinses, $\mathrm{Og}$ completely inhibited the growth of all the organisms, Streptococcus viridans and S. albus respectively implicated for gingivitis and dental caries. ${ }^{35}$ Despite these studies had been in vitro and the likelihood of possibility of change in activity of microflora of a patient cannot be ruled out as it function in vivo, the antimicrobial action was confirmed in the present clinical study.

Volatile oils constitute a group of plant secondary metabolites which can best be obtained through hydrodistillation and some has potent antimicrobial effects. ${ }^{35}$ The major constituents found in $O g$ and previously known for its antimicrobial activity are eugenol and thymol. ${ }^{16}$

The action mechanism of eugenol occurs in plasmatic membrane level and is attributed to cellular lipids alterations; lost of intracellular material and inhibition of nucleic acid synthesis. ${ }^{36}$ Helander et $\mathrm{al}^{37}$ attributed the thymol antimicrobial action to its phenolic character, which can cause membrane-disturbing activities. These data support the antiplaque effect of $O g$ founded in the present work and are in agreement with others studies that investigated other herbal products with similar constituents. ${ }^{13,14}$

The test groups reduced gingivitis significantly at the end of the trial, in which the $\mathrm{Og}$ group presented just $8 \%$ of the sites with bleeding and CLX group 6\%. Nevertheless, this percent difference was not significant showing that this herbal agent had potential similar to chlorhexidine as antiseptic agent. The BI is a generally used dichotomous index to evaluate gingivitis, ${ }^{11,13,15}$ but it does not access the severity of gingival inflammation. Studies evaluating the reduction of gingivitis by a grading index could be interesting to complement these results, as used in other works evaluating herbal agents. ${ }^{14,30}$ However, color change used as parameter in this grading index cannot be necessarily an accurate indicator of gingivitis. ${ }^{15}$

The anti-inflammatory activity demonstrated by $\mathrm{Og}$ might be due to the presence of flavonoids in its composition. ${ }^{20}$ This component inhibits phosphodiesterases which are involved in cell activation, and their effects depend upon the biosynthesis of protein cytokines that mediate adhesion of circulating leucocytes to the sites of injuries. ${ }^{20}$ In addition, extracts of $\mathrm{Og}$ appeared to improve the phagocytic function without affecting the humoral or cell-mediated immune system, showing its immunobiological activity. ${ }^{17}$ In spite of these explanations, the exact mechanism of its anti-inflammatory action is hidden yet and more studies are necessary. ${ }^{20}$ 
Home-use mouth rinses studies are often influenced by a number of factors which can mask the superiority of a test agent over the controls. Participants in clinical trials may experience some improvement associated not specifically to the therapeutic properties of the test agent but rather related to a behavior change- - Hawthorne effect. ${ }^{15}$ Subjects enrolled in oral hygiene studies usually improve their tooth brushing, irrespective of the product they receive. ${ }^{15}$

Although the volunteers of the present study were not conscious of which mouth rinse they were using, another main factor is the Novelty effect which is the motivation on oral hygiene practice by the use of a new substance. In contrast, lack of compliance in the correct use of mouth rinse can occur as well. ${ }^{15}$ In order to minimize its event, the participants were asked to bring the bottle at the end of the trial, so we could evaluate indirectly subject compliance. Reduction on gingivitis in both test groups showed that they used the mouth rinse correctly.

Finally, the results showed that $O g$ was an effective antiplaque and antigingivitis herbal agent in a similar manner of chlorhexidine digluconate and it should be advantageous in cases where patients have little motor skills and tooth brushing is compromised. However, laboratorial analysis, such as immunoenzymatic assays of gingival crevicular fluid, would be needed to a better understanding of the role of $O g$ as an effective agent on gingivitis control. Further clinical studies must be performed to evaluate the action of this herbal agent in other oral diseases, such as chronic periodontitis.

\section{CONCLUSION}

Within the limits of this clinical study, it may be concluded that the mouth rinse containing $O g$ was effective in the plaque and gingivitis control, comparable to chlorhexidine digluconate.

\section{CLINICAL SIGNIFICANCE}

Research in treatment of chronic oral diseases using natural agents must be encouraged to verify which would be a useful addition to the current range of chemotherapeutic treatment options.

\section{REFERENCES}

1. Hugoson A, Sjödin B, Norderyd O. Trends over 30 years, 19732003, in the prevalence and severity of periodontal disease. J Clin Periodontol 2008;35:405-14.

2. Franco Neto CA, Parolo CCF, Rösing CK, Maltz M. Comparative analysis of the effect of two chlorhexidine mouth rinses on plaque accumulation and gingival bleeding. Braz Oral Res 2008;22:139-44.
3. Axelsson P, Lindhe J, Nyström B. On the prevention and caries and periodontal disease. Results of 15-year longitudinal study in adults. J Clin Periodontol 1991;18:182-89.

4. Löe $H$, Theilade E, Jensen SB. Experimental gingivitis in man. J Periodontol 1965;36:177-87.

5. Nogueira-Filho GR, Toledo S, Cury JA. Effect of 3 dentifrices containing triclosan and various additives. An experimental gingivitis study. J Clin Periodontol 2000;27:494-98.

6. Moran J, Addy M, Newcombe RG, et al. A study to assess the plaque inhibitory action of a newly formulated triclosan toothpaste. J Clin Periodontol 2001;28:86-89.

7. Palomo F, Wantland L, Sanchez A, et al. The effect of three commercially available dentifrices containing triclosan on supragingival plaque formation and gingivitis: A six-month clinical study. Int Dent J 1994;44:75-81.

8. Yates R, Jenkins S, Newcombe RG, et al. A 6-month usage trial of $1 \%$ chlorhexidine toothpaste. (1) Effects on plaque, gingivitis, calculus and toothstaining. J Clin Periodontol 1993;20:130-138.

9. Quirynen M, Avontroodt P, Peeters W, Pauwels M, Coucke W, Van Steenberghe D. Effect of different chlorhexidine formulations in mouthrinses on de novo plaque formation. $\mathrm{J}$ Clin Periodontol 2001;28:1127-36.

10. Lee SS, Zhang W, Li Y. The antimicrobial potential of 14 natural herbal dentifrices: Results of an in vitro diffusion method study. J Am Dent Assoc 2004;135:1133-41.

11. Salgado ADY, Maia JL, Pereira SLS, et al. Antiplaque and antigingivitis effects of a gel containing Punica Granatum Linn extract. A double-blind clinical study in humans. J Appl Oral Sci 2006;14:162-66.

12. Sastravaha G, Gassmann G. Sangtheraplitikul P, et al. Adjunctive periodontal treatment with Centella asiatica and Punica granatum extracts in supportive periodontal therapy. J Int Acad Periodontol 2005;7:70-79.

13. Botelho MA, Nogueira NAP, Bastos GM, Fonseca, et al. Antimicrobial activity of the essential oil from Lippia Sidoides, carvacrol and thymol against oral pathogens. Braz J Med Biol Res 2007;40:349-56.

14. Rodrigues ISCR, Tavares VN, Pereira SLS, Costa FN. Antiplaque and antigingivitis effect of Lippia Sidoides. A double-blind clinical study in humans. J Appl Oral Sci 2009;17:404-07.

15. Oliveira SMA, Torres TC, Pereira SLS, Mota OML, Carlos MXC. Effect of a dentifrice containing aloe vera on plaque and gingivitis control. J Appl Oral Sci 2008;16:293-96.

16. Sartoratto A, Machado ALM, Delarmelina C, Figueira GM, Duarte MCT, Rehder VL. Composition and antimicrobial actvity of essential oils from aromatic plants used in Brazil. Braz J Microbiol 2004;45:275-80.

17. Faria TJ, Ferreira RS, Yassumoto L, Souza JRP, Ishikawa NK, Barbosa AM. Antifungal activity of essential oil isolated from Ocimum gratissimum L. (eugenol chemotype) against phytopathogenic fungi. Braz Arch Biol Tech 2006;49:867-71.

18. Nweze EI, Eze EE. Justification for the use of Ocimum gratissimum $\mathrm{L}$ in herbal medicine and its interaction with disc antibiotics. BMC Compl Alternat Med 2009;9:1-6.

19. Nakamura CV, Nakamura TU, Bando E, Melo AFN, Cortez DAG, Filho BPD. Antibacterial activity of Ocimum gratissimum L essential oil. Mem Inst Oswaldo Cruz 1999;94:675-78.

20. Tanko Y, Magaji GM, Yerima M, Magaji RA, Mohammed A. Antinociceptive and anti-inflammatory activities of aqueous leaves extract of Ocimum gratissimum (Labiate) in rodents. Afr J Trad CAM 2008;5:141-46. 
21. Ainamo J, Bay I. Problems and proposals for recording gingivitis and plaque. Int Dent J 1975;25:229-35.

22. Turesky S, Gilmore ND, Glickman I. Reduced plaque formation by the chloromethyl analogue of victamine C. J Periodontol 1970;41:41-43.

23. Pereira SLS, Lima MSS, Costa FN, Carlos MX, Kayatt FE. Evaluación del efecto de un gel conteniendo extracto de aruera en el tratamiento de gingivitis. Estudio clínico em humanos. Acta Odontol Ven 2009;47:1-8.

24. Ernst CP, Prockl K, Willershausen B. The effectiveness and side effects of $0.1 \%$ and $0.2 \%$ chlorhexidine mouth rinses: A clinical study. Quintessence Int 1998;29:443-48.

25. Quirynen M, Soers C, Desnyder M, Dekeyser C, Pauwels M, van Steenberghe D. A 0.05\% cetyl pyridinium chloride/0.05\% chlorhexidine mouth rinse during maintenance phase after initial periodontal therapy. J Clin Periodontol 2005;32:390-400.

26. Lang NP, Hotz P, Graf H, Geering AH, Saxer UP, Sturzenberger O. Effects of supervised chlorhexidine mouthrinses in children. A longitudinal clinical trial. J Periodontal Res 1982;17:101-11.

27. Segreto VA, Collins EM, Beiswanger BB, de la Rosa M, Isaacs RL, Lang NR. A comparison of mouth rinses containing two concentrations of chlorhexidine. J Periodontal Res 1986;21: 23-32.

28. Pereira SLS, Barros CS, Salgado THY, Filho VPP, Costa FN. Limited benefit of Copaifera oil on gingivits progression in humans. J Contemp Dent Pract 2010;11:57-64.

29. Hebbar SS, Harsha VH, Shripathi V, et al. Ethnomedicine of Dharwad district in Karnataka, India-plants used in oral health care. J Ethnopharmacol 2004;94:261-66.

30. Pai MR, Acharya LD, Udupa N. Evaluation of antiplaque activity of Azadirachta indica leaf extract gel - a 6-week clinical study. J Ethnopharmacol 2004;90:99-103.

31. Sokovic M, Glamoclija J, Marin PD, Brkic D, van Griensven LJ. Antibacterial effects of the essential oils of commonly consumed medicinal herbs using an in vitro model. Molecules. 2010;27:15:7532-46.

32. Thaweboon S, Thaweboon B. In vitro antimicrobial activity of Ocimum americanum L. essential oil against oral microorganisms. Southeast Asian J Trop Med Public Health. 2009;40:1025-33.

33. Silva MRM, Oliveira JG Jr, Fernandes OFL, Passos XS, Costa CR, Souza LKH, et al. Antifungal activities of Ocimum gratissimum towards dermatophytes. J Ethnopharmacol 2005;48:72-86.
34. Lemos JA, Passos XS, Fernandes OFL, Paul JR, Ferri JP, Ferri $\mathrm{PH}$, et al. Antifungal activities of Ocimum gratissimum towards Cryptococcus neoformans. J Ethnopharmacol 2005;20:4-13.

35. Ahonkai I, Ayinde BA, Edogun O, Uhuwmangho MU. Antimicrobial activities of the volatile oils of Ocimum bacilicum L. and Ocimum gratissimum L. (Lamiaceae) against some aerobic dental isolates. Pak J Pharm Sci 2009;22:405-09.

36. Laekeman GM, Hoof LV, Haemers A. Eugenol a valuable compound for in vitro experimental research and worthwhile for further in vivo investigation. Phytoth Res 1990;90-96.

37. Helander IM, Alakomi HL, Latva-Kala K, Mattila-Sandholm T, Pol I, Smid EJ, et al. Characterization of the action of selected essential oil components on Gram-negative bacteria. J Agric Food Chem 1998;46:3590-95.

\section{ABOUT THE AUTHORS}

\section{Sérgio Luís da Silva Pereira}

Professor, Department of Periodontics, Dental School, University of Fortaleza, Brazil

\section{José Weslley Gonçalves de Oliveira}

Graduate Student, Department of Dentistry, University of Fortaleza Brazil

\section{Keyles Karla Sá Vieira Ângelo}

Graduate Student, Department of Dentistry, University of Fortaleza Brazil

\section{Ângela Maria Alves da Costa}

Graduate Student, Department of Pharmacy, University of Fortaleza Brazil

\section{Flávio Costa}

Master in Science in Health Education, Professor of Organic Chemistry, University of Fortaleza, Brazil

\section{CORRESPONDING AUTHOR}

Sérgio Luís da Silva Pereira, Av Engenheiro Leal Lima Verde, 2086 Alagadiço Novo, Fortaleza, CE, Cep: 60830-055, Brazil, Phone: +55 85 34744108, Fax: +55 85 34773259, e-mail: luiss@unifor.br 